\title{
Inmigración e identidad colectiva. Reflexión sobre la identidad en el País Vasco
}

\author{
Cristina Blanco Fernández de Valderrama \\ Universidad del País Vasco. Facultad de Ciencias Sociales y de la Información. \\ Departamento de Sociología. Barrio Sarriena, s/n. 48940 Leioa (Vizcaya). Spain
}

\section{Resumen}

El enfoque dominante en el estudio de la inmigración se caracteriza fundamentalmente por el carácter unilateral de los procesos de ajuste y adaptación sociocultural. Los inmigrantes son tratados, generalmente, como objetos pasivos de las transformaciones a que dan lugar las dinámicas interactivas. Dentro de éstas, la definición de la identidad colectiva constituye un elemento de importancia sustancial. En este campo de las relaciones interculturales asumimos que la inmigración es uno de los principales factores generadores de contacto inzercultural; que la identidad colectiva no es un fenómeno estático, sino producto de la interacción entre los miembros de una comunidad, así como de sus condicionantes historicos, $y$ que el inmigrante, cuando se configura como fuerza importante de población (inmigración masiva) no es un mero objeto pasivo, sino sujeto activo de las transformaciones sociales de la comunidad receptora.

Bajo tales presupuestos, en este artículo se pretende analizar la telactón existente entre la inmigración y la identidad colectiva de la sociedad receptora, aplicada, en este caso, al contexto de la comunidad vasca. Dentro de este encorno, nuestro propósito es reflexionar sobre el papel que ha desempeñado, y sigue desempenando, la inmigración en el proceso de construcción-reconstrucción de la identidad colectiva vasca.

Palabras clave: grupos étnicos, inmigración, identidad colecriva, relaciones interculturales.

Abstract. Immigration and collective identity. A consideration of identity in the Basc Country

The article analyses the relationship between immigration and collective identity of the receiving society, with special attention to the Basc Country. In this context immigration contributes to the process of construction and reconstruction of basc collective identity.

Key words: ethnic groups, inmigration, collective idencity, intercultural relations.

\section{Sumario}

1. Idencidad colectiva

2. Identidad colectiva e inmigración
3. Pats Vasco: la reestructuración de su identidad

4. Bibliografia 
La inmigración, en cuanto fenómeno de masas, se enfrenta cara a cara con los sentimientos y la conciencia de identidad colectiva. El hecho de que sobre una comunidad, una vez definidos los términos de su propia existencia como tal, recaiga una inmigración masiva de gentes pertenecientes a la categoría de los "otros", ha de suponer, indefectiblemente, una alteración del equilibrio conseguido y una redefinición de los términos de la identidad del nuevo grupo resultante. La interdependencia entre los fenómenos sociales de la inmigración y la identidad colectiva viene definida por una doble acción recíproca:

a) La adaptación de los inmigrantes al nuevo entorno social va a depender, en gran medida, de la identidad colectiva sustentada por el grupo que los recibe, en tanto en cuanto esta identidad define el marco de relaciones sociales entre los miembros reconocidos como tales frente a los que no lo son.

b) La identidad del grupo humano receptor de masas importantes de inmigrantes queda, a su vez, afectada por esta afluencia de gentes reconocidas como diferentes, dado que en las sociedades modernas la identidad colectiva no es un objeto estático de referencia, sino una construcción dinámica permanente.

\section{Identidad colectiva}

\subsection{Concepto}

El concepto de identidad hace relación a la percepción de uno mismo y de los demás. Las dicotomías igual-diferente, dentro-fuera, propio-extraño, yo-otro, explican la esencia de la identidad, tanto individual como colectiva. Esta requiere no sólo del "nosotros», sino también del kotro» frente al cual el individuo o grupo se autoafirma como diferente. La identidad individual o grupal se construye mediante la diferenciación de sí mismo por comparación a otros. Esta igualdad (yo) - diferencia (otro), como elemento constitutivo de la identidad, se asienta sobre determinados rasgos objetivos que dan cuerpo, caracterizándolo, al individuo o grupo. Estos elementos pueden ser de naturaleza diversa (en el caso de los grupos: lengua, raza, territorio, historia, etc.) y la importancia atribuida a cada uno de ellos puede variar a lo largo de la vida del grupo.

Además de la relación inseparable igualdad-diferencia y de los rasgos objetivos sustentadores de identidad, existe un tercer elemento constitutivo de este proceso definidor del sujeto o grupo: la conciencia de identidad como sentimiento de pertenencia. En el caso de los grupos humanos este sentimiento es de suma importancia dadas sus implicaciones sociales: lo importante no es la racionalidad u objetividad en que descansa la conciencia de pertenencia a un colectivo ('hay razones objetivas que sostengan este sentimiento de pertenencia?), sino su fuerza social para imponerse como factor de integración grupal y como organizador de interacción social ${ }^{1}$.

1. Véase F. Barth (1976) y las obras de A. Pérez-Agote (1982, 1984, 1990), para quien esta idea constituye uno de los ejes centrales de sus reflexiones sobre la identidad colecriva. 
La identidad a la que aquí nos referimos es aquella que se deriva de la existencia (real o simbólica) de unos rasgos culturales que, por su exclusividad, generan en los miembros del grupo una conciencia de diferencia asumida $y$ compartida. Los rasgos esenciales de la identidad colectiva así entendida podrían resumirse de la forma siguiente:

- existencia de una colectividad;

- que adquiere conciencia de singularidad, y por lo tanto de diferenciación, con respecto a otras colectividades;

- en base a una elección (construcción social) de determinados elementos caracteristicos, generalmente culturales, como sustentadores de tal singularidad;

- siendo esta construcción social un proceso variable en el tiempo y en el espacio.

\subsection{Las adhesiones etnoterritoriales en la modernidad}

No han sido pocos los que, en los útimos tiempos, han venido augurando el derrumbamiento de las adscripciones etnoterritoriales como consecuencia de un supuesto proceso racionalizador universal, que muchos denominan modernización. La progresiva interdependencia mundial, con el acercamiento y mestizaje cultural que ello comporta, ha llevado a muchos teóricos sociales a vaticinar el cercano final de las lealtades locales o nacionales, consideradas más propias de mundos mágico-tribales que de sociedades regidas por la racionalidad científica. El resultado de tal proceso incontrovertible sería el triunfo del «nosotros" universal materializado en la idea de la "Aldea global" con una cultura homogeneizante y transnacional ${ }^{2}$.

Lo cierto es que la sentencia de muerte de los particularismos, proveniente de ámbitos tan dispares como las teorías de la modernización o del marxismo, no parece haber encontrado todavía el momento apropiado para su aplicación. Los acontecimientos vertiginosos de la Europa del Este, el desmembramiento de la antigua Unión Soviética, e incluso los escollos encontrados para la unificación de la Europa occidental, dan buena muestra de que las adhesiones nacionalistas, en tanto que movimientos étnicos con pretensiones de autogobierno, ni han muerto ni parece que vayan a hacerlo en un futuro próximo.

El hombre parece abocado a la identificación grupal y al deseo de singularidad (C. Lisón, 1982). Lo que varía en función del tiempo histórico es el carácter y el proceso generador de identidad colectiva. Así, Jürgen Habermas (1981), preguntándose por la posibilidad de desarrollar una identidad racional en las sociedades complejas, centra la atención en su génesis dentro de este tipo de sociedades. Frente a las tradicionales, donde la identidad colectiva era

2. Véase a este respecto la obra colectiva, editada por Mike Featherstone (1990), sobre la "Cultura globaln. 
un hecho dado e integrador del individuo, grupo y naturaleza en una unidad indivisible, las sociedades modernas desarrollan una identidad dinámica y flexible, en la que los actores sociales forman parte activa en su gestación. El proceso es descrito en los siguientes términos:

[...] los individuos mismos toman parte en el proceso de formacion [...] de una identidad sollo esbozable en común. La racionalidad de los contenidos de identidad se mide entonces sólo en base a la estructura de este proceso de generación, esto es: a las condiciones formales de realización y comprobación de una identidad flexible en las que todos los miembros de la sociedad puedan reconocerse y respetarse recíprocamente (J. Habermas, 1981:100).

La identidad colecriva es, por tanto, un proceso de construcción permanente en el que los actores sociales, o algunos de ellos, se convierten en protagonistas. En este entramado analítico y conceptual, que asumimos plenamente, nos movemos al reflexionar sobre la identidad colectiva y la inmigración. Así, los grandes movimientos migratorios tendrian como consecuencia una reformulación de la identidad colectiva de la sociedad receptora, al producir una variación sustancial en las condiciones de existencia de dicha sociedad. Sólo entendiendo la identidad colectiva como algo dinámico y construible se puede explicar la variedad de fórmulas de adhesiones comunitarias y la posibilidad de integración de nuevos miembros en una sociedad que, en principio, les reconoce como diferentes.

\section{Identidad colectiva e inmigración}

\subsection{Los inmigrantes en tanto que pertenecientes a la categoria de los otros}

En el contexto de un "nosotros" más o menos definido, más o menos consciente, más o menos objetivado, aparece la afluencia de gentes extrañas que interfieren en la vida cotidiana del grupo: los "otros". Así, la inmigración puede constituir un elemento generador de sentimientos de amenaza contra la propia supervivencia del grupo originario ${ }^{3}$.

El problema de la identidad colectiva —afirma Pérez-Agote- no es el problema de la identidad de la sociedad consigo misma, sino el problema de la conciencia de identidad, que precisamente es más probable que aparezca frente a la amenaza, es decir, en la crisis y en el cambio traumático (A. Pérez-Agote, 1984:26).

Esteva Fabregat, por su parte, manifiesta la posibilidad de un conflicto interétnico como resultado de los movimientos migratorios, ya que "remueven la idea de seguridad y estabilidad” (C. Esteva Fabregat, 1984:38). Este conflic-

3. Condicionantes de la tolerancia intergrupo: definición, evaluación y seguridad del grupo (J.W. Berry, R. Kalin y D.M. Taylor, 1977). 
to puede materializarse en la discriminación mediante el extrañamiento sociał debido, más que a diferencias de estatus económico u ocupacional, a diferencias de etnicidad. Este antropólogo catalán desarroila una teoría del conflicto étnico estableciendo sus bases en dos puntos fundamentales: la diferencia cultural y la interferencia social y pragmática de una cultura en el proceso histórico de otra.

$\mathrm{La}$ inmigración es uno de los factores más importantes desencadenantes de este posible conflicto interétnico, por cuanto altera el equilibrio preexistente en la formación y mantenimiento de la identidad colectiva, tanto en sus aspectos objetivos como de conciencia. La identidad colectiva sustentada por los miembros de los grupos en interacción, ejercerá una fuerza determinante sobre los procesos de integración de los inmigrantes en la sociedad receptora. Los resultados de estos procesos pueden ser variados, siendo los más conocidos la asimilación el "melting pos y el pluralismo cultural (C. Blanco, 1990).

El mantenimiento de una fuerte identidad colectiva por parte de la sociedad receptora inclinará las relaciones hacia la asimilación de los inmigrantes. Esta tendencia se verá reforzada por muchos otros factores (similitud cultural entre ambos colectivos, homogeneidad étnico-cultural de la sociedad de adopción, tiempo de permanencia de los inmigrantes, etc. $)^{4}$. Por otro lado, la existencia de una fuerte identidad colectiva en los diferentes grupos en interacción producirá una inestabilidad, una tensión, en la que ninguno de ellos querrá renunciar a la pertenencia a su grupo, pugnando por investir a su cultura del rango de oficialidad, o cuando menos de supervivencia.

El análisis de la inmigración en una sociedad determinada no debe limitarse a uno de los flujos interactivos (situación de la cultura minoritaria), sino a ambos, es decir, también a la influencia que la inmigración ejerce sobre la sociedad receptora. Esta influencia, limitándonos al nivel que nos ocupa (la identidad colectiva), adquiere una gran importancia si se quieren entender los procesos de generación y modificación de las identidades colectivas en aquellas sociedades afectadas fuertemente por la inmigración.

\subsection{Influencia de la inmigración sobre la identidad colectiva de la sociedad receptora}

En el caso hipotético de la asimilación, el problema de la identidad colectiva parece resolverse por sí mismo. Los grupos asimilados adquieren la cultura y las formas de vida de la nueva sociedad, convirtiéndose así en miembros igualitarios de ésta, en parte del "nososotros" colectivo. De igual modo, en el proceso del melting pot la construcción de la nueva sociedad por aportaciones de todos los grupos ha de originar una nueva identidad que aglutine a todos los coparticipantes del proyecto social, integrándolos también en un mismo "nosotros".

4. Sobre los condicionantes de la asimilación pueden consultarse: N. Glazer y D.P. Moynihan (1963), L.W. y M. Shannon (1967), M. Gordon (1964), R. Taft (1986), encre otros. 
El problema se suscita si tenemos en cuenta que estos resultados de la interacción mencionados no parecen responder a la realidad. Existe la comprobación generalizada de que ni la asimilación ni el melting pot se producen como fenómenos globales y perdurables en el tiempo, además de ser concebidos como no deseables ${ }^{5}$. La forma de convivencia intercultural alternativa es el pluralismo cultural. La coexistencia de la diversidad cultural nos lleva al planteamiento de la unificación de los miembros de una sociedad multicultural en una única colectividad, en el reconocimiento mutuo como partes integrantes de la misma, evitando aś la ruptura o la disgregación. La conexión de la forma pluralista con la identidad colectiva plantea serios problemas que han de resolverse para evitar el peligro de confrontación cultural entre grupos que, cuando menos en una primera etapa, se reconocen diferentes en el seno de una misma sociedad.

La identidad de los inmigrantes de primera generación puede preservarse en los mismos términos que en su lugar de origen, pero las generaciones sucesivas, si no han quedado totalmente asimiladas, pueden sufrir una crisis de identidad ${ }^{6}$. Su participación en una mezcla de culturas y de grupos de pertenencia requiere necesariamente una síntesis integradora que les haga sentirse miembros de la comunidad en la que se encuentran, sin tener la sensación de renunciar a algo que les es propio. Esta construcción activa no sólo afecta al individuo o grupo en minoría, sino a toda la sociedad pluricultural. Para superar la fragmentación, se debe crear una identidad común que una a todos los miembros por encima de particularidades culturales. La definición de tal identidad integradora, que no ha de suponer la eliminación de diferencias, es tarea ineludible de las sociedades plurales modernas.

La idea de identidad colectiva como proceso dinámico que observábamos en Habermas se presenta aquí con fuerte vigencia. También Schlesinger hablará de la elaboración de la identidad nacional como proceso crónico en el que se entabla una dinámica relacional entre el pasado y el presente de una colectividad nacional, y en el que hay que considerar el «rol especial de los productores culturales como constructores activos de la identidad nacionaln (P. Schlesinger, 1987:261).

La preocupación por el análisis de los procesos de generación dinárnica de la identidad colectiva constituye el núcleo del Coloquio Internacional de Toulouse en 1979: "Identités Collectives et Changements Sociaux». En la introducción al Coloquio, Pierre Tap afirmaría: «sólo el movimiento y la renovación evitarán de hecho la muerte real o simbólica de la identidad" (P. Tap, 1980:12).

5. W.D. Borrie (1959), N. Glazer y D.P. Moynihan (1963), J.W. Berry y otros (1977), J. Crispino (1980), A.P. Royce (1982), CH. Hirschman (1983), C.U. Schierup y A. Âlund (1987), J. Castillo Castillo (1990), etc.

6. Este aspecto de desequilibrio y marginalidad ha sido descrito por Stonequist en su conocida obra El hombre marginal (1961). Véase también G. Simmel (1950) y A.V. Cicourel (1983). 
En este movimiento continuo de reajuste de la identidad colectiva nacional, no sólo los inmigrantes experimentan cambios en la concepción de sí mismos, sino que será la sociedad en su conjunto la que sufra adaptaciones sucesivas hasta integrar en el "nosotros" a todos los miembros en interacción.

Afrrmamos, por tanto, que la inmigración masiva constituye un fenómeno que obliga a la redefinición de los términos de identidad nacional del grupo que la recibe, siempre y cuando no se produzca una asimilación completa o una separación absoluta entre las diversas colectividades.

\section{País Vasco: la reestructuración de su identidad}

La sociedad vasca es un claro ejemplo de debate interno librado en aras de la redefinición de una identidad nacional que concilie su pasado con su presente. La llegada masiva de inmigrantes, ajenos a los imperativos tradicionales del "ser vasco", en un momento de profunda crisis de identidad, agudizará el conflicto iniciado a finales del XIX y alimentará de forma especialmente virulenta el sentimiento de amenaza de la propia identidad.

\subsection{Contexto histbrico: crisis de identidad e inmigracion ${ }^{7}$}

Las transformaciones sufridas desde el último tercio del siglo XIX, removedoras de los cimientos mismos de una sociedad tradicional, rural, profundamente religiosa, étnicamente homogénea y con una cultura e instituciones propias, crearán un marco singularmente adverso para la convivencia entre autóctonos e inmigrantes. La "desvasquización» comienza a ser un hecho, fruto de la concurrencia de factores que van a atacar, desde diversos flancos, la existencia del pueblo vasco, tal y como venía siendo desde siglos atrás. La conciencia de la pérdida de la propia identidad empieza a ser latente antes de manifestarse con toda su futerza, y objetivarse políticamente, en la figura de Sabino Arana ${ }^{8}$. Sólo desde la comprensión del alcance y rapidez con que estos fenómenos operaron en zonas clave de Euskadi, se puede entender la actitud hacia los inmigrantes, la cual marcaría la convivencia mutua durante muchos años.

Industrialización y abolición de los Fueros son acontecimientos clave de este proceso sentido como "desvasquización" del pueblo vasco. En palabras de Solozábal, el industrialismo supuso:

la puesta en cuestión de los fundamentos étnicos y culturales del pueblo vasco como tal [...]. La poda foral de 1876 [...] produjo en el País Vasco un sentimiento generalizado de incomprensión y frustración, proporcionando la ocasión para la reflexión sobre su situación y destino como pueblo (J.J. Solozábal, 1979:15).

7. Vease al respecto la reciente tesis doctoral de Xabier Aierdi (1993). La inmigración en el espacio social vasco.

8. Sobre la tesis de la pérdida de identidad véase J.J. Solozábal (1979) y J. Corcuera (1979). 

minos:

Otro estudioso de esta época histórica vasca se expresa en parecidos tér-

Es 1876 el inicio de una nueva situación social y política: el gobierno de las provincias pasatá a la oligarquía industrial y financiera, la industrialización exige una importación masiva de mano de obra extraña al Pais, el intervencionismo del Estado central se incrementa, la sociedad tradicional vasca entra en su definitiva crisis [...]. Este será el matco en el que Arana y Goiri formulará su nacionalismo (J. Corcuera, 1979:58).

La inmigración hacia el País Vasco, y en particular hacia Vizcaya, llega con los primeros pasos de la industrialización; pero es con la abolición de los Fueros cuando ésta va a ser multitudinaria. Para este entonces el clima contra los uespanoles» se empieza a hacer manifiesto. El "antimaketismon formulado por Sabino Arana será la culminación de esta aversión por todo aquello que es identificado como culpable de la degeneración del tradicional ser vasco: España y los españoles ${ }^{9}$. En este estado de cosas, nadie oculta la dificultad de la convivencia entre nativos e inmigrantes desde sus inicios:

Industrialización e inmigración plantean en Euskal Herria un enfrentamiento entre dos comunidades étnicamente diferentes (la autóctona y la inmigrante) (J. Corcuera, 1979:384).

Las dificultades de integración en el mundo cultural vasco favorecían el matrimonio entre no vascos (J.J. Solozábal, 1979:44).

La desconfranza mutua entre vascos e inmigrantes impide la interacción fluida, cuando no genera conflicto más o menos virulento. Este conflicto pronto fue instrumentalizado políticamente, apareciendo dos corrientes claramente contrapuestas: el nacionalismo y el socialismo. Ciertamente, el aumento progresivo del proletariado junto al rechazo sistemático de los inmigrantes provenientes de tierras españolas, fue un estupendo caldo de cultivo para el enraizamiento de un sólido movimiento socialista ${ }^{10}$.

El rumbo de este sistema de relaciones experimentó un giro sustancial con la instauración del régimen franquista. Tras la guerra civil se impuso en el Estado español un sistema centralista, homogeneizador y tendente a la eliminación forzosa de toda peculiaridad y diferencialidad de las comunidades integrantes. Pero lejos de obtener una nación española, en el sentido de generar un sentimiento nacional unificado en todo el Estado español, la persecución de

9. El término "maketo" fue acufado por el fundador del Partido Nacionalista Vasco para designar a los inmigrantes españoles afincados en tierras vascas. Sobre la imagen que se renía de ellos es interesante acercarse a la obra de Sabino Arana Goiri. Una recopilación de sus escritos más importantes es la editada por L. Haramburu Ed. (San Sebastián, 1978): Obras Completas. Vease sobre todo el aparrado "Jaungoikoa".

10. Véase P. Rivas (1979). "Las relaciones entre el socialismo alemán y español". Esnudios de Historia Social núm. 8-9, p. 227-286. 
las nacionalidades periféricas consiguió reforzar las diferencias previas existentes. La discriminación impuesta en 1937 a "las provincias traidoras» otorgó a este territorio perseguido la condición de particularidad. Es el propio Estado quien confiere significación social al territorio diferenciado (A. PérezAgote, 1984:79-80).

La diferencia del pueblo vasco permanece en las conciencias durante el franquismo, pero dada la represión de toda manifestación pública en este sentido, este sentimiento ha de refugiarse en la esfera privada, imposibilitando así su natural discurrir histórico" ${ }^{11}$. La aparición del nacionalismo radical y de ETA abrirá un nuevo estadio en el conflicto para el reconocimiento del País Vasco como nacionalidad. Junto a los acontecimientos políticos de esta época se producen hacia Euskadi nuevas afluencias migratorias masivas.

Todo ello ha contribuido a la no superación, mediante una espontánea dinámica intercultural, de una crisis de identidad. Por un lado se produce una rápida desvasquización no deseada; por otro, la imposibilidad de sustituir de forma natural y gradual los viejos elementos nacionalistas por otros más adecuados a los tiempos históricos. La instauración de un sistema democrático, incluyendo formulas de autogobierno, ha abierto de nuevo la posibilidad de devolver al País Vasco la personalidad histórica deseada. ¿Cómo ha evolucionado esta crisis de identidad y qué papel ha desempeñado la continua afluencia de inmigrantes hasta nuestros días? Para tratar de contestar a éste y otros interrogantes utilizaremos los resultados de una reciente encuesta que en su día realizamos a una muestra representativa de la población vasca mayor de 18 años $^{12}$. En dicha encuesta, aplicada a 1.400 individuos de toda la Comunidad Autónoma Vasca durante el mes de julio de 1991, se abordan los problemas de identidad a través de indicadores tales como singularidad percibida del pueblo vasco, criterios de pertenencia o identidad asumida en diferentes entornos comunitarios.

\subsection{La redefinición de la identidad vasca}

\subsubsection{Composición actual de la poblacion}

La continua afluencia de inmigrantes del resto del Estado español hacia el País Vasco durante décadas ha configurado un panorama complejo de población. No sólo la tercera parte de la población vasca es inmigrante, sino que existen ya tres generaciones de inmigrantes asentadas en territorio vasco; se trata de sujetos nacidos en el Pás Vasco pero cuyos padres y/o abuelos fueron inmigrantes en su df́a. Por otro lado se ha producido también una multiplicidad de combinaciones de filiación a que ha dado lugar la exogamia durante todas estas décadas. Utilizando la composición de la muestra, a faita de información

11. Sobre este tema véase A. Pérez-Agote (1984, 1987) y A. Gurrutxaga (1985a, 1985b).

12. La encuesta citada consiruye la base de la investigación aAnálisis trigeneracional de la integración sociocultural del inmigrante en el País Vascon realizada para la Comisión Interministerial de Ciencia y Tecnología, y dirigida por $\mathrm{J}$.I. Ruiz Olabuenaga. 
censal con respecto a la ascendencia de origen de la población, se observa que los grupos más numetosos son los tipos resultantes de matrimonios endogámicos (de padres y abuelos):

- Nativo trigeneracional (nativo de padres y abuelos nativos): $32,95 \%$ del total de la muestra.

- Inmigrante (inmigrantes de primera generación): $31,2 \%$.

- Segunda generación (nativo de ambos padres inmigrantes): 16,0\%.

Los nativos de ambos padres nativos y todos los abuelos inmigrantes son escasos, dado que la tercera generación de inmigrantes es aún muy limitada en cualquiera de las combinaciones posibles. El conjunto de estos tres tipos de población supone el $80 \%$ de la muestra. Al presentar los resultados de los indicadores de identidad por grupos de ascendencia utilizaremos tan sólo los dos primeros, porque lo que nos interesa aquí es conocer las posibles diferencias y su evolución en el seno de la población vasca de ascendencia y la inmigrante, evitando la implicación de problemas intermedios como los producidos por el nacimiento en la sociedad receptora con ascendencia ajena a la misma, sea ésta total o parcial.

\subsubsection{Singularidad vasca y criterios de pertenencia}

Desde la elaboración de la doctrina política de Sabino Arana, bajo el lema "Jaun-Goikua eta Lagi-Zára" (Dios y Ĺey Vieja), hasta nuestros días han pasado casi cien años. Desde entonces la búsqueda de la nueva identidad nacional vasca ha constituido un proceso vivo de redefinición de sus contenidos que hagan comparible la existencia del pueblo vasco como tal con su realidad social. Los elementos definidores de Euskal Herria, legitimadores de su condición de nacionalidad, futeron en un primer momento los siguientes:

- Raza: se asumía la existencia de una raza vasca, la cual habría de mantenerse en toda su pureza.

- Lengua: el euskera como lengua propia y diferente constituye el segundo rasgo definidor de la nación vasca, pero siempre supeditado a la raza, con lo cual se evita su posible adquisición por parte de quienes no tienen orígenes vascos.

- Gobierno y leyes. los Fueros se presentan como sistema de autogobierno.

- Carácter y costumbres cuyo rasgo más definidor es la profunda religiosidad $\mathrm{y}$ un sistema de valores tradicional.

- Personalidad historica; la independencia secular del territorio vasco, sin perjuicio de las uniones voluntarias a Castilla, le confere una especificidad histórica.

El principal rasgo definidor de un vasco de entonces era su pertenencia a la raza, sus orígenes, sus ancestros, objetivados mediante los apellidos. Constituía éste un elemento objetivo, adscrito y absoluto de pertenencia que delimitaba 
con claridad la frontera entre el "nosotros" y los "otros". Pero la realidad social de convivencia cotidiana entre estas dos categorías en una misma comunidad forzó, desde los inicios de la industrialización, a la reformulación de estas fronteras. La cultura va a desempeñar un papel crucial como elemento de diferenciación colectiva, a la que se unirá la reimplantación de instituciones que dotan al territorio de ciertas cotas de autogobierno. Ahora bien, ¿qué ha sucedido con el sentimiento de pertenencia y con los condicionantes sustentadores de la misma? ¿Cuáles son los presupuestos actuales para considerarse y ser considerado vasco? ¿Existe una fuerte conciencia de identidad colectiva vasca? Desde las instancias políticas, nacionalistas o no, radicales o no, el actual discurso dominante (se plasme o no en las actitudes y comportamientos individuales y/o colectivos) es la pertenencia a la comunidad vasca desde una óptica generalizada; esto es, el vasco es todo aquel que viva y trabaje en el País Vasco y/o el que, sin más, se sienta como tal. Esta uniformización de la postura discursiva, tendente a evitar el fraccionamiento de la sociedad vasca, supone un cambio sustancial del esencialismo nacionalista tradicional. Pero hace falta saber si la pretendida solución integradora ha calado hondo en la base social vasca.

Ante estas cuestiones iniciales tres son los elementos a dilucidar a través de los resultados de la investigación sobre inmigración vasca anteriormente citada.

a) Conciencia actual de la singularidad del pueblo vasco.

b) Elementos que sustentan tal singularidad.

c) Criterios dominantes de pertenencia y su comparación con los tradicionales.

Con respecto al primer punto, y ante la pregunta de si considera el entrevistado que existen diferencias sustanciales entre vascos y no vascos, los resultados generales y de los dos grupos seleccionados son los siguientes.

Tabla 1. Conciencia de singularidad (\%).

\begin{tabular}{lccc}
\hline $\begin{array}{l}\text { Diferencia entre } \\
\text { vascos y no vascos }\end{array}$ & $\begin{array}{l}\text { Total } \\
\text { muestra }\end{array}$ & Inmigrantes & $\begin{array}{l}\text { Nativos } \\
\text { trigeneracionales }\end{array}$ \\
\hline SI & 59,6 & 54,5 & 63,3 \\
NO & 40,3 & 45,3 & 36,7 \\
NS/NC & 0,1 & 0,2 & - \\
\hline Total & $\mathbf{1 0 0 , 0}$ & $\mathbf{1 0 0 , 0}$ & 100,0 \\
& $(1.400)$ & $(437)$ & $(460)$ \\
\hline
\end{tabular}

La conciencia mayoritaria es de que el pueblo vasco es diferente, sustancialmente, al resto de los pueblos españoles. Pero dicha conciencia no es igualmente compartida. El origen y ascendencia nativa o inmigrante pesa considerablemente en la sustentación de la singularidad de la comunidad 
vasca. Ciertamente son los nativos de ascendencia vasca los que más abiertamente expresan tal singthlaridad. Los inmigrantes, sin embargo, presentan una mayor diversificación de opiniones.

En cuanto a las características del pueblo vasco que le diferencian de los demás, se presentó en el cuestionario una lista cerrada ante la cual el entrevistado tenía que elegir las que consideraba más significativas en primer y segundo lugar. Utilizaremos sólo las elegidas en primera opción y las agruparemos de la forma siguiente:

- Esenciales derivadas del propio discurrir histórico e independienres de la voluntad de los miembros del grupo. Cultura, lengua, historia y raza pertenecen a esta categoría.

- Adquiridas. resultantes de las anteriores. La historia, la raza, la cultura imprimen al grupo un carácter, una forma de ser, un modo de entender la vida. Pertenecen a esta categoría, por tanto, el modo de ser y la religiosidad.

- Volitivas dependientes de la voluntad de los miembros de un grupo de diferenciarse de los demás, de constituirse y/o permanecer como unidad comunitaria singular. La voluntad de mantenerse como pueblo y las actitudes políticas se inscriben en esta última categoría.

Tabla 2. Características del pueblo vasco, según su naturaleza (\%).

\begin{tabular}{lccc}
\hline Características & $\begin{array}{c}\text { Total } \\
\text { muestra }\end{array}$ & Inmigrantes & $\begin{array}{l}\text { Nativos } \\
\text { trigeneracionales }\end{array}$ \\
\hline Esenciales & 67,0 & 65,3 & 70,7 \\
Adquiridas & 14,1 & 13,9 & 15,2 \\
Volitivas & 18,6 & 20,6 & 14,1 \\
NS/NC & 0,3 & 0,2 & - \\
\hline Total & 100,0 & 100,0 & 100,0 \\
& $(1.400)$ & $(\mathbf{4 3 7 )}$ & $(460)$ \\
\hline
\end{tabular}

Existe una sensación generalizada de que el pueblo vasco se diferencia de los demás por su propio discurrir histórico. El pueblo vasco se concibe, por tanto, con personalidad propia, pero, de nuevo, el origen y ascendencia de la poblacion imprimen una forma diferente de percibir esta realidad comunitaria. En ambos grupos extremos de población se cumple la creencia en la esencialidad del pueblo vasco, pero más notablemente entre los vascos de ascendencia. El colectivo inmigrante otorga al pueblo vasco una importante singularidad basada en la propia voluntad de sus miembros. Los nativos "puros" están más convencidos de que sus particularidades no reposan en la mera voluntad, sino en características objetivas de diferenciación y en el modo de ser que éstas han imprimido durante su largo discurrir como pueblo.

Sabemos, por tanto, que la muestra analizada defiende la particularidad del pueblo vasco, basada en características objetivas. Ahora bien, ¿Cuáles son los criterios dominantes de pertenencia a esta comunidad diferenciada? Para 
conocerlos se ofreció a los entrevistados una lista de posibles condiciones para considerarse y ser considerado vasco, pidiéndoles que eligiesen la más importante según su criterio. Estas condiciones hacen alusión a tres dimensiones sensiblemente diferentes en su grado de inclusión/exclusión:

- Inclusión generat considera vasco a todo sujeto que se asiente en el País Vasco, por el mero hecho de su participación en la vida colectiva vasca. Es, en realidad, una definición de ciudadanía. "Vivir y trabajar en el Pás Vasco" es la formulación de tal condición general de pertenencia.

- Inclusión en base a un compromiso personal: restringe la pertenencia a la demostración individual del propio deseo de pertenencia. A pesar de que se exige algún requisito, éste puede ser satisfecho por cualquier ciudadano, sea cual sea su origen. Las formulaciones que pertenecen a esta categoría son las siguientes: "amar la tierra", "saber euskera, aún sin nacer en el País Vasco" y "Ser nacionalista vasco".

- Inclusión en base al origen o ascendencia supone una restricción de la pertenencia a los sujetos vinculados por ascendencia y/o nacimiento a la comunidad vasca. Esta fórmula de adscripción se compone de las siguientes formulaciones: "nacer en el País Vasco", "nacer aquí y saber euskera" y udescender de familia vasca».

Tabla 3. Criterios de pertenencia (\%).

\begin{tabular}{lccc}
\hline Inclusión & $\begin{array}{l}\text { Total } \\
\text { muestra }\end{array}$ & Innigrantes & $\begin{array}{l}\text { Nativos } \\
\text { trigenetacionales }\end{array}$ \\
\hline General & 14,1 & 22,6 & 9,8 \\
Compromiso & 53,6 & 46,0 & 53,9 \\
Origen/ascendencia & 32,0 & 30,9 & 36,1 \\
NS/NC & 0,4 & 0,5 & 0,2 \\
\hline Total & 100,0 & 100,0 & 100,0 \\
& $(1.400)$ & $(437)$ & $(460)$ \\
\hline
\end{tabular}

De los datos generales se desprenden los siguientes hechos:

- Se ha producido en el seno de la sociedad vasca un cambio en los criterios de inclusión/exclusión. El origen y ascendencia no son ya determinantes para ser un ciudadano reconocido como vasco.

- La pretendida inclusión generalizada en la categoría del "vasco" propuesta desde las instituciones e instancias políticas no es, cuando menos en la actualidad, un sentimiento dominante en la ciudadanía vasca.

- El "ser" vasco se deriva de una demostración voluntarista del deseo de pertenencia.

- No existe un acuerdo consensuado en lo referente a la definición de "vasquidad». Las opciones son diversas, encontrando cada una de ellas importante sustento social: poco más de la mitad de los entrevistados cree que es nece- 
sario demostrar, de algún modo, su deseo de pertenencia; un tercio considera que el vasco es el nacido y/o descendiente de vascos y el I $4 \%$ restante considera que vasco es el que "vive y trabaja" en Euskadi. La heterogeneidad de definiciones de la "vasquidad" es un hecho en ruestra realidad social actual, lo cual puede estar demostrando dos cosas: o que la redefnición de los criterios de pertenencia es un proceso aún inacabado, o que nos encontramos ante una situación de indefinición más o menos sostenida. Podríamos hablar de pluralidad si el criterio dominante de inclusión admitiera diferentes formas de sentirse vasco, pero siempre aglutinando bajo esta categoría a la totalidad de los ciudadanos vascos, sea cual sea su origen. Es decir, la pluralidad se refiere a las formas de sentirse miembro, no a las propia calidad de miembro. Obviamente este no es el caso, ya que un $32 \%$ de los encuestados reserva la categoría de "vasco" a quien pertenece por nacimiento o ascendencia al propio territorio.

La comparación entre ambos grupos de población según su origen eminentemente vasco o inmigrante nos revela, además, que existe una forma diferenciada de percibir la "vasquidad". Los vascos no sustentan la idea de la "vasquidad" generalizada y apuestan por el compromiso y por el origen/ascendencia. Los inmigrantes presentan una división interna mucho más acusada. Un tercio se autoexcluye de la comunidad vasca; casi un cuarto defiende la adquisición indiscriminada de la "vasquidad", y el $46 \%$ restante se inclina por la demostración voluntarista del deseo de pertenencia. En cualquier caso existe un solapamiento en la diferenciación de las percepciones: no sólo existen diferencias inter-grupos, sino también intra-grupos.

\subsubsection{El papel de la inmigración y de las relaciones interculturales}

Resumamos los hechos y los presupuestos fundamentales vistos hasta el momento, a fin de conocer el papel de la inmigración en la redefinición de la identidad vasca. En cuanto a los hechos, dos son los que nos interesa destacar:

- La existencia de una composición heterogénea de la población en cuanto a sus orígenes como resultado de la inmigración.

- El desplazamiento de los criterios dominantes de pertenencia tradicionales (restrictivos) por otros más integradores.

Los presupuestos fundamentales que guían nuestro análisis son los siguientes:

- La identidad colectiva de los pueblos no es un rasgo estático, sino una construcción dinámica permanente.

- En una situación de interacción, como resultado de los movimientos migratorios, el inmigrante no es el único elemento afectado por los reajustes necesarios. La población autóctona, en virtud de tal interacción, también se verá afectada transformando sus presupuestos iniciales. Todo ello, siempre y 
cuando no se produzca una absorción total de uno de los grupos por parte del otro (asimilación), o cuando los grupos en cuestión no desarrollen formas paralelas de subsistencia (separación).

El primero parece confirmarse en el caso vasco. El segundo presupuesto es lo que trataremos de comprobar ahora. Se trata, en definitiva, de saber qué variaciones se han producido en el seno de la sociedad vasca debidas a la incorporación de grandes masas de inmigrantes. ¿El contacto muruo continuado genera variaciones en los modos de percibir la "vasquidad", en la sustentación de los criterios que la definen?

Dado que no podemos observar las variaciones sufridas en la identidad de los ciudadanos vascos a lo largo de diferentes períodos históricos, intentaremos comprobarlas a través de los propios sujetos de la encuesta, dividiendo los grupos según su mayor o menor sometimiento al contacto mutuo. En base al presupuesto del contacto intercultural deberían observarse diferencias dentro de los propios nativos (por grupos de edad) y dentro de los propios inmigrantes (por tiempo de residencia). Utilizaremos tan sólo un indicador de identidad: las condiciones para considerarse y considerar a los demás como pertenecientes a la comunidad étnica vasca ${ }^{13}$.

Sabemos que entre vascos e inmigrantes existe una diferente definición de la pertenencia. ¿Cómo ha variado cada grupo, si lo ha hecho, durante su relación con el otro? ¿La interacción ha acercado posturas? ¿Las ha alejado? ¿Las mantiene iguales? Los inmigrantes con menos tiempo de residencia han tenido menos oportunidad de contactar con la población autóctona. Por su parte, los inmigrantes más antiguos han tenido mucho más tiempo para la interacción con los vascos.

El cuestionario, aplicado en 1991, recoge el tiempo de residencia en base a tres etapas migratorias: los llegados antes de 1950 (con más de 41 años de convivencia), los llegados entre 1950 y 1975 (con un período de convivencia entre 16 y 41 años) y los llegados después de 1975 (con menos de 16 años de residencia). Lógicamente es muy importante tener en cuenta no sólo los años de residencia, sino el lugar en el que se ha llevado a cabo la socialización primaria del sujeto. En muchos casos se produce la situación de una corta estancia en la sociedad receptora pero con una socialización primaria producida en ella (inmigrantes llegados en su primera infancia). Para evitar la posible distorsión que pudiera producir la socialización primaria en el País Vasco se elegirán a los sujetos cuya edad al llegar fue de 10 o más años. En base a este criterio, los grupos de inmigrantes quedan como sigue:

- Llegados antes de 1950. aquellos que llevan más de 4 I ańos residiendo en el País Vasco y cuya edad actual es superior a los 51 años.

- Llegados entre 1950 y 1975: con un tiempo de residencia entre 16 y 41 años $y$ con una edad actual mayor de 25 años.

13. En el sentido de grupo étnico definido por Barth y ouros, no biologista. 
- Llegados después de 1975: con menos de 16 años de residencia y cuya edad actual es de 18 años o más (dado que la encuesta se dirigío a la población de 18 años en adelante).

Tabla 4. Criterios de pertenencia. Inmigrantes llegados con 10 años o más, por períodos migratorios (\%).

\begin{tabular}{lccc}
\hline & Antes de & & Después de \\
Inclusión & 1950 & $1950-1975$ & 1975 \\
\hline General & 25,0 & 24,4 & 23,9 \\
Compromiso & 42,3 & 41,8 & 41,3 \\
Origen/ascendencia & 32,7 & 33,8 & 34,8 \\
\hline Total & 100,0 & 100,0 & 100,0 \\
& $(52)$ & $(213)$ & $(46)$ \\
\hline
\end{tabular}

Eliminados los casos NS/NC.

La distribución de los criterios de inclusión/exclusión es prácticamente idéntica en los tres grupos de inmigrantes, to cual indica que los inmigrantes no varían los criterios en función del tiempo de residencia en el País Vasco. Es decir, el llevar muchos años de convivencia con la población autóctona no ha supuesto una variación en la percepción de la "vasquidad" de los inmigrantes.

Hay que tener en cuenta, sin embargo, el factor edad: los inmigrantes más antiguos han de presentar, por fuerza, una estructura de edades mucho más envejecida (en este caso todos son mayores de 51 años) que los ilegados con posterioridad. Para evitar el posible efecto de la edad, comprobaremos los criterios defendidos por uno de los grupos de inmigrantes por grupos de edad. Elegiremos el contingente intermedio de inmigrantes (llegados entre 1950 y 1975), ya que es el más numeroso (posibilita la desagregación) e incluye a la población inmigrante que en la actualidad cuenta con más de 26 años.

Tabla 5. Criterios de pertenencia. Inmigrantes llegados entre 1950 y 1975 con 10 años o más, por grupos de edad (\%).

\begin{tabular}{lcc}
\hline Inclusión & De 26 a 50 años & Más de 50 años \\
\hline General & 26,0 & 22,6 \\
Compromiso & 36,5 & 46,2 \\
Origen/ascendencia & $37,5 \quad 31,1$ \\
\hline Total & $100,0100,0$ \\
& $(104)(106)$ \\
\hline
\end{tabular}

Eliminados los casos NS/NC.

Pese a que a simple vista pudiera parecer que existen diferencias en el seno de este grupo por categorías de edad, hay que considerar que tales diferencias no son estadísticamente significativas. Aplicando el test del CHI cuadrado el resultado es que la asociación entre las dos variables presenta una alta proba- 
bilidad de error $(p=0,35)$. Por tanto, podemos decir que los inmigrantes no varían su definición de la uvasquidad" en función del tiempo de residencia y convivencia entre vascos. Este hallazgo es de gran importancia. Si bien la tendencia general es de creer que los inmigrantes son los que se adecúan a los modos y maneras de la sociedad receptora, en el caso del Pafs Vasco y en el terreno de la identidad (expresado mediante los criterios defendidos de inclusión/exclusión) tal presupuesto no se cumple.

Nos cabe pensar que la interacción entre la cultura vasca y las restantes españolas en el seno de la sociedad vasca afectará, entonces, a la población nativa. Por población nativa entenderemos la que posee ascendencia vasca (ambos padres y los cuatro abuelos vascos), puesto que es en ella donde se debe sopesar la posible evolución de criterios de pertenencia de los vascos como consecuencia de la interacción social con los inmigrantes, evitando la problemática de la umarginalidad" étnica (mestizaje) brillantemente expuesta por Simmel, Park y Stonequist. La posible evolución o cambio se estudiará mediante la desagregación de esta población en grupos de edad. Estos grupos serán los siguientes:

- De 18 a 25 años. Nacidos después de 1965, cuando la inmigración es ya un hecho, y socializados en un ambiente de creciente apertura. La transición política española y la configuración autonómica del Estado cogen de lleno a estas generaciones de vascos.

- De 26 a 50 años. Son los vascos nacidos entre 1941 y 1965 , cuando la afluencia inmigratoria está en su verdadero apogeo. Es, por otro lado, la época det franquismo más duro, donde cualquier manifestación de identidad «separatistan era fuertemente perseguida. Estos vascos no sólo han convivido con la inmigración durante largas décadas, sino que ésta ha sido un elemento constitutivo mismo de la sociedad que les ha visto nacer.

- De más de 50 años. constituyen las generaciones nacidas antes de 1941. Es una época de grandes cambios, de incertidumbre. La nueva inmigración aún no se había dejado sentir, y la vieja (de principios de siglo) se había vivido como una verdadera amenaza a la identidad y a la supervivencia del pueblo vasco. Sin embargo, este grupo de vascos son los que más tiempo han convivido con la inmigración (véase tabla 6 ).

Tabla 6. Criterios de pertenencia. Nativos de ascendencia vasca, por grupos de edad (\%).

\begin{tabular}{lccc}
\hline Inclusión & $\begin{array}{l}\text { Menos de } \\
26 \text { años }\end{array}$ & $\begin{array}{l}\text { Entre } \\
26 \text { y } 50 \text { años }\end{array}$ & $\begin{array}{l}\text { Más de } \\
50 \text { años }\end{array}$ \\
\hline General & 10,0 & 13,7 & 6,1 \\
Compromiso & 53,0 & 56,0 & 52,5 \\
Origen/ascendencia & 37,0 & 30,3 & 41,3 \\
\hline Total & 100,0 & 100,0 & 100,0 \\
& $(100)$ & $(175)$ & $(179)$ \\
\hline
\end{tabular}

Eliminados los casos NS/NC. 
Aunque las diferencias se pueden apreciar con la simple observación de los datos, éstas se confirman estadísticamente: existe asociación entre la edad y los criterios de inclusión defendidos por la población nativa de ascendencia vasca, con un nivel de confianza del $92 \%$ (CHI $2=8,35 ; \mathrm{GL}=4 ; \mathrm{p}=0,08$ ). Dicho de otro modo, los vascos varian notablemente la definición de "vasquidad" según su edad.

Los más viejos son los que menos dispuestos están a conceder el calificarivo de "vasco" a todo aquel que viva y trabaje en el territorio, De igual modo, son los que consideran en mayor medida que lo vasco está asociado al nacimiento y a la ascendencia familiar. Los vascos de edades intermedias presentan otro esquema diferente: son los más propensos a aceptar como vasco a cualquier citudadano que resida en el país; por contra, son los que menos creen en el "esencialismo" étnico (origen/ascendencia). Por último, los más jóvenes vutelven a acercarse a las posturas de los más viejos, si bien de un modo más moderado y tendente a una mayor posibilidad de integración de los no nacidos vascos. ¿Qué se puede inferir de tales resultados? Dos hechos fundamentales:

- La población de ascendencia vasca ha variado sus criterios de «vasquidad» con el paso del tiempo, medido en este caso mediante la edad de los entrevistados.

- Estas variaciones no se deben al contacto intercultural ni a la convivencia con la inmigración, a diferencia de lo que cabria esperar, sino a las condiciones bistóricas que a cada generación le ba tocado vivir, tanto de carácter general como con respecto a los inrmigrantes y a su identidad. Esto se justifica desde el momento en que la expectativa de a mayor edad más convivencia con inmigrantes y, por lo tanto, más capacidad de incluirlos en la propia categoría de "vasquidad" simplemente no se cumple. La evolución del discurso inclusivo en los actuales nativos de ascendencia vasca no sigue una trayectoria ni ascendente ni descendente, lo que quiere decir que no es la edad de los sujetos (ni sus años de interacción con los inmigrantes) lo que sustenta tal evolución. Cabe pensar que en los vascos de más edad, a pesar de haber convivido con la inmigración la mayor parte de su vida, pesan notablemente sus orígenes y la situación kistorica previa a la dictadura. En los vascos de edades intermedias parece pesar el hecho de la inmigración como presión demográfica; nacen y se socializan en una sociedad vasca plagada de inmigrantes y donde la identidad esencialista vasca no puede asomar casi ni siquiera en las esferas familiares. La inmigración parece un hecho y con ello hay que contar. Los más jóvenes han vivido una situación diferente. Se encuentran también con la inmigración como hecho, peto el entorno socio-político ha cambiado mucho. Es la hora de reivindicar la propia identidad, de sacarla a la calle, de evitar la continua "desvasquización" del país de sus ancestros. Es una época en la que se perfila nítidamente la revitalización de dos tendencias opuestas: la de los nacionalismos, la apuesta por la singularidad, por una parte, y la de las ideas universalistas derivadas de la creciente interdependencia internacional, la tecnología y la comunicación, por otra. 


\subsection{Conclusiones}

Los datos analizados sobre los criterios de pertenencia al pueblo vasco nos conducen a las siguientes conclusiones fundamentales:

1. Los criterios de pertenencia han sufrido un desplazamiento desde la inclusión restrictiva (ascendencia-origen) de principios de siglo hasta la inclusión posibilista (el deseo de ser). La inclusión integradora potenciada desce el discurso político no es dominante en la sociedad vasca.

2. Este desplazamiento indica que la identidad colectiva es una construcción dinámica en función de los acontecimientos históricos y de los agentes sociales intervinientes. En el caso del País Vasco, el proceso hacia una redefinición relativamente consensuada del «ser» vasco está aún por concluir, habida cuenta de la heterogeneidad de criterios presentes incluso dentro de cada grupo originario de población.

3. En este desplazamiento de los criterios de pertenencia la inmigración ha jugado un papel fundamental, pero no por su capacidad interactiva con la población autóctona, sino por su potencialidad demográfica. Los inmigrantes, en virtud de su presencia numérica en la sociedad vasca, han desplazado los criterios de pertenencia hacia posiciones más posibilistas.

4. Los cambios observados tras años de contacto intergrupal se producen tan sólo entre los nativos y no entre los inmigrantes. Los inmigrantes, por tanto, no acusan una influencia derivada del contacto con la población nativa. En el caso de los nativos de ascendencia vasca, aunque cambian sus presupuestos de "vasquidad" con la edad, este cambio tampoco se debe al contacto con la población inmigrante, sino más bien al propio fenómeno migratorio (incorporación de grandes masas de inmigrantes) rodeado de diferentes contextos socio-politicos.

5. Cabe hipotetizar que, a pesar de los años de convivencia mutua, las vidas grupales de nativos e inmigrantes discurren más de modo paralelo que interactivo; es decir, existen indicios de que entre nativos e inmigrantes se produce un extrañamiento social quizá derivado de las reminiscencias esencialistas de un pasado no lejano.

\section{Bibliografía}

AIERDI, Xabier (1993). La inmigración en el espacio social vasco. Bilbao: UPV.

ARANA Goiri, Sabino (1978). Obras Completas. San Sebassián: L. Haranburu Ed.

BARTH, Fredrik (Comp) (1976). Los grupos étnicos y sus fronteras. México: Fondo de Cultura Economica.

BERRY, J.W.; KAIIN, R y TAYLOR, D. (1977). Multiculturalism and etbnic attitudes in Canada. Otawa: Minister of Supply and Services.

BlanCO, Cristina (1990), La integración de los inmigrantes en Bilbao. Bilbao: Ayuntamiento de Bilbao.

BORRIE, W.D. (1959). The cultural integration of immigrants. Unesco. 
CASTILlO Castillo, José (1990). "Teorías sociológicas de las migraciones humanas: diversidad e integración. XII Congreso Mundial de Sociología. Madrid, 9-13 de julio (sin publicar).

CICOUREL, Aaron V. (1983). "Vivit entre dos culturas: el universo cotidiano de los trabajadores migrantesm. En VVAA. Vivir entre dos culturas. Barcelona: Serbal/Unesco, p. 32-92.

CORCUERA, Javier (1979). Origenes, ideologia y organizacion del nacionalismo vasco 1876-1904. Madrid: Siglo XXI.

CRISPINO, J. (1980). The assimilation of ethnic groups: the italian case. Nueva York: Center for Migration Studies.

DUMONT, Louis (1988). "El individuo y las culturas, o cómo la ideología se modifica por su misma difusión". En TODOROV, T. Cruce de culturas y mestizaje cultural. Madrid: Ed. Júcar, p. 159-172.

ESTEVA FABREGAT, Claudi (1984). Estado, etnicidady biculturalismo. Barcelona: Península.

GELLNER, Emest (1964). Thought and change. Londtes: Weidenfeld \& Nicolson.

GLAZER, N. y MOYNIHAN, D.P. (1963). Beyond the melting pot. Massachusetts: MIT Press.

GORDON, Milton (1964). Assimilation in American life. Nueva Xork: Oxford University Press.

GURRUTXAGA, Ander (1985a). El cbdigo nacionalista vasco durante el franquismo. Barcelona: Anthropos.

- (1985b). "El conflicto nacional y la realidad vasca". En VV.AA. Autodeterminación de los pueblos. Un reto para Euskadi y Europa. Biibao: Herria 2000 Eliza, p. 177-194.

HABERMAS, Jürgen (1981). La reconstrucción del Materialismo Histórico. Madrid: Taurus.

- (1989). Identidades nacionales y postnacionales. Madrid: Tecnos.

HiRSCHMAN, Charles (1983). "America's melting pot reconsidered". Annual Review of Sociology, vol. 9, p. 397-423.

KEDOURiE, Elie (1985). Nacionalismo. Madrid: Centro de Estudios Constitucionales.

KREJCl, Jarosiav (1978), "Ethnic problems in Etrope". En GINER, S. y SCOTTFORD, M. Contemporary Europe. Londres: Routledge \& Kegan Paul, p. 124-171.

LAIN ENTRALGO, Pedro (1983). Teoria y realidad del otro. Madrid: Alianza.

LISON TOLOSANA, Catmelo (1982). "La singularidad plural. Antropología cultural y especificidad". REIS, núm. 18, p. 7-27.

MARTIN RAMirez, J. y SUlLIVAN, R. (1987). "The basque conflicr". En BOUCHER, J. y otros. Etbnic conflict. International perspectives. Londres: Sage Publications, p. $120-138$.

MERCADE, Francesc (1986). "España como problema. Reflexiones sobre identidad". En HERNANDEZ, F. y MERCADE, F. (Comps.). Estructuras sociales y cuestión nacional en España. Barcelona: Ariel, p. 15-27.

MOYA, Carlos (1984), "Identidad colectiva: un programa de investigación empírica". REIS, núm. 25, p. 7-35.

PEREZ-AGOTE, Alfonso (1982). «La identidad colectiva: noción sociológica y dimensión polftica». En Garmendia, J.A. y otros. Abertzales y vascos. Madrid: Akal, p. 13-31.

- (1984). La reproducción del nacionalismo. El caso vasca. Madrid: Centro de Investigaciones Sociologicas.

- (1987). El nacionalismo vasco a la salida del franquismo. Madrid: CIS. 
RIVAS, P. (1979). "Las relaciones entre el socialismo alemán y español». Estudios de Historia Social, núm. 8-9, p. 227-286.

ROIZ, Miguel (1981). "Identidad y conciencia regional y nacional de los pueblos de España. Documentación Social núm. 45, p. 29-55.

ROYCE, A.P. (1982). Ethnic identity: strategies of diversity. Indiana: University Press. Ruiz OlabuenaGA, J.I. y BlanCO, C. (1994). La inmigración vasca. Análisis trigeneracional de 150 años de inmigración. Bilbao: Universidad de Deusto.

SCHERUP, C.U. y ALUND, A. (1987). Will they still be dancing? Estocolmo: Almqvist \& Wiksel International.

SCHLESINGER, Philip (1987). "On national identity: some conceptions and misconceptions criticized". Social Science Information, vol. 26, núm. 2, p. 219-264.

SHANNON, L.W. y M. (1967). "The assimilation of migrants to cities: anthropological and sociological contributions". En SCHNORE, L.F. y FAGIN, H. (eds.), Urban researchs and policy planning. California: Sage Publications, p. 49-75.

SIMMEL, Georg (1950). "The stranger". WOLFE, K. (Ed.). The sociology of Georg Simmel. Glencoe: Free Press.

SMITH, Anthony D. (1976). Las teorias del nacionalismo. Barcelona: Península.

SOLO7ABAL, J.J. (1979). El primer nacionalismo vasco. Industrialismo y conciencia nacio nal. San Sebastián: Haranburu.

STONEQUIST, E.V. (1961). The marginal man: a study in personality and culture confict. Nueva York: Russell \& Russell.

TAFT, Ronald (1986). "Methodological considerations in the study of immigrant adaptation in Australia". Australian Journal of Psichology, vol. 38, núm. 3, p. 339-346.

TAP, Pierre (1980). Identites collectives et changements sociatux. Toulouse: Privars.

WILliamS, C.H. (1982), "Introduction". En WILliams, C.H. (Ed.). National Separatism. Canadá: University of Wales Press, p. 1-16. 